\title{
Parents' relationship to pain during children's cancer treatment - a preliminary validation of the Pain Flexibility Scale for Parents
}

\author{
This article was published in the following Dove Press journal: \\ Journal of Pain Research \\ 3 March 2017 \\ Number of times this article has been viewed
}

\author{
Jenny Thorsell Cederberg' \\ Sandra Weineland \\ Strandskov ${ }^{2}$ \\ JoAnne Dahl ${ }^{3}$ \\ Gustaf Ljungman' \\ 'Department of Women's and \\ Children's Health, Uppsala University, \\ Uppsala, ${ }^{2}$ Närhälsan, Research and \\ Development Center, Primary \\ Health Care, Södra Älvsborg, Borås, \\ ${ }^{3}$ Department of Psychology, Uppsala \\ University, Uppsala, Sweden
}

Objectives: Pain is one of the most frequent and burdensome symptoms for children with cancer. Psychological acceptance has been shown to be beneficial in chronic pain. Acceptancebased interventions for experimentally induced pain have been shown to predict increased pain tolerance and decreased pain intensity. An acceptance-based pilot study for children with cancer experiencing pain has shown promising results. Further, parental acceptance has been shown to predict decreased child distress. To date, no instruments measuring acceptance in the context of acute pain in children are available. The aim of this study was to develop and evaluate an instrument to measure acceptance in parents of children experiencing pain during cancer treatment. Methods: A test version of the Pain Flexibility Scale for Parents (PFS-P) was sent to parents of all children undergoing cancer treatment in Sweden at the time of the study. Exploratory factor analysis $(n=243)$ examined numerous solutions. Internal consistency, test-retest reliability and convergent validity were calculated.

Results: A three-factor Promax solution best represented the data. The subscales were pain resistance, valued action and pain fusion. Internal consistency was good $(\alpha=0.81-0.93)$, and the total scale and the subscales demonstrated temporal stability $(r=0.76-0.87)$ and good convergent validity $(-0.40$ to -0.84$)$.

Discussion: The PFS-P measuring acceptance in parents of children experiencing pain during cancer treatment is now available, enabling evaluation of acceptance in the context of acute pain in children. The scale shows good psychometric properties but needs further validation.

Keywords: acute pain, children, parents, acceptance, psychological flexibility, factor analysis

\section{Introduction}

Pain is one of the most frequently reported symptoms for children undergoing cancer treatment. ${ }^{1}$ The causes of pain are commonly the disease itself, side effects of treatment and medical procedures. ${ }^{2}$ Pain is associated with psychological distress for the children, and this in turn increases the pain experience. ${ }^{3-7}$ Psychological acceptance has been shown to be beneficial for persons suffering from chronic pain. ${ }^{8-10}$ Psychological acceptance of chronic pain is defined as living with pain without reacting to, judging or attempting to reduce or avoid it. ${ }^{11}$ It involves an active willingness to engage in meaningful activities in the presence of pain in the service of living a vital valued life. An acceptance-based psychological treatment, acceptance and commitment therapy (ACT), has been shown to improve psychosocial and physical functioning in adults and children with chronic pain. ${ }^{12,13}$ ACT aims to create psychological flexibility around
Correspon

Department of Women's and Children's Health, Uppsala University, Uppsala University Hospital, SE-75I 85 Uppsala, Sweden

Tel +46 18 6II 0197

Fax +46 I8 508680

Email jenny.thorsell.cederberg@kbh.uu.se 
difficult experiences to enable moving forward in life as opposed to getting stuck in avoidant behavior. ${ }^{14}$ In the ACT model, acceptance is one of the processes underpinning psychological flexibility. For pain that has been experimentally induced, different acceptance-based interventions have been shown to predict increased pain tolerance and decreased pain intensity and experienced unpleasantness of pain. ${ }^{15-22}$ The common denominator of these interventions is the cultivation of an attentive, non-reactive stance toward unpleasant stimuli with the aim to merely observe ongoing experiences without further mental processing in contrast to attempting to control or distract, corresponding to the process of acceptance. ${ }^{23,24} \mathrm{~A}$ pilot study of an acceptance-based intervention for children experiencing pain during cancer treatment is currently being undertaken at the Children's University Hospital in Uppsala, Sweden, showing promising results (J Thorsell Cederberg, MS, unpublished data, October 2016). Psychological acceptance is the proposed mechanism of change in the intervention. Studying and understanding mechanisms of change in the evaluation of therapeutic interventions guides optimization of treatment change. ${ }^{25}$ Several instruments measuring acceptance in chronic pain have been reported. ${ }^{26-28}$ To date, no instrument for measuring acceptance in the context of acute pain has been reported. The development of such an instrument would enable the investigation of acceptance as a possible mediating variable of acceptance-based interventions for those experiencing acute pain.

The role of the parent in interventions targeting children has been emphasized regarding both pediatric cancer ${ }^{29}$ and pediatric pain. ${ }^{30}$ Having a child undergoing cancer treatment infers a great deal of psychological distress for parents. ${ }^{31-33}$ Parent distress and behavior affect levels of distress and coping in the child, ${ }^{34-39}$ and parental acceptance has been shown to predict lower levels of child distress..$^{40,41}$ Developing and evaluating an instrument measuring parental acceptance would be helpful in investigating the mediating processes of psychological treatments targeting acute pain in children.

In summary, acceptance-based interventions could potentially help children experiencing pain during cancer treatment. The evaluation of acceptance as the mediating variable of such an intervention is dependent on an instrument for measuring acceptance of acute pain. Further, since parental acceptance may affect child distress and coping, an instrument for measuring this is essential. The aim of this study was to develop an instrument to measure parental acceptance in the context of acute pain in children with cancer.

\section{Methods}

\section{Participants and procedures}

The target population was parents of all children aged 0-18 years, being treated for cancer in Sweden at the time of the study. Children undergoing cancer treatment were identified by the Swedish Childhood Cancer Registry. Four hundred and eighty-five patients were identified. In one case, patient information was insufficient and the patient was therefore excluded. The six pediatric oncology centers in Sweden were consulted to ensure that parents of children who had gone into palliation or deceased after data withdrawal from the register were not contacted. One patient was then identified as undergoing palliation and therefore excluded as a result of this screening. Parents of 483 children were thus contacted and offered participation in the study. Information about the study along with two sets of the study material was sent out via mail to the registered address. As thanks for their participation in the study, the parents were included in a lottery of ten movie tickets. Consent was implied by participation in the study. The study material consisted of background information, the test version of the acceptance scale, evaluation questions and two measures for validation. A reminder was sent out 2 weeks after the first dispatch. For test-retest analysis, the measures were sent out again after a month. All study material was coded and hence de-identified. A code key was kept during data collection for administrative purposes. Two hundred and forty-six parents participated in the study of which 117 parents participated in both measurements and 129 participated in only one measurement. Parents of 160 children participated in the study, which corresponds to $34 \%$ of the children. For 85 of the children, both parents responded, for 75 one parent responded. Three were excluded due to incorrect completion of the measures. Two parents only filled in the background information and one of the validation measures at the first measurement, and hence not the test scale, and were not sent the test-retest material. One parent filled in the first measurement (M1) jointly with the other parent, which led to exclusion of that measurement, and did not fill in the test-retest measurement (M2), which the other parent did. Three other couples filled in M1 conjointly, and these measurements were excluded, but M2 was filled in separately and hence valid. Two hundred and forty-three participants were included in the analyses. Twenty-five parents (of 23 children) declined. Nine dispatches were returned by the postal service. No response was received from parents of 205 children. Two test-retest measurements came in 8 months late and were not included in the study. Figure 1 shows the participants flow, and a demographic overview is shown in 


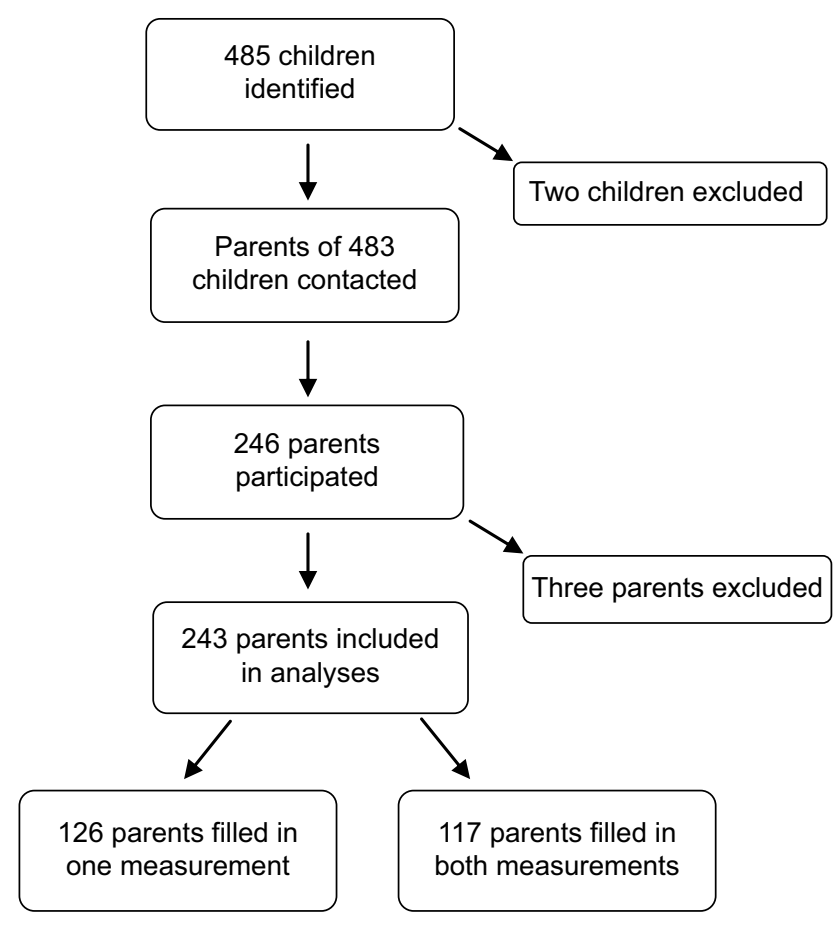

Figure I Participants' flow.

Table I Gender, age and diagnosis group of children and gender of parent

\begin{tabular}{|c|c|c|c|c|c|c|}
\hline & $\widehat{~}(\%)$ & q (\%) & $\begin{array}{l}\text { Mean } \\
\text { age (SD) }\end{array}$ & $\begin{array}{l}\text { Age } \\
\text { range }\end{array}$ & Diagnosis & \\
\hline \multirow[t]{3}{*}{$\begin{array}{l}\text { Children } \\
(n=\mid 58)\end{array}$} & 88 (55.7) & $70(44.3)$ & $7.58(5.12)$ & $0-18$ & Leukemias & 81 \\
\hline & & & & & Brain tumors & 20 \\
\hline & & & & & Solid tumors & 57 \\
\hline Parents & 96 (39.5) & 147 & & & & \\
\hline$(n=243)$ & & $(60.5)$ & & & & \\
\hline
\end{tabular}

Abbreviation: SD, standard deviation.

Table 1. The study was approved by the Regional Ethical Committee in Uppsala, Sweden (Dnr 2014/375).

\section{Background information}

Background information included relationship to the child, age and gender of the child, type and date of diagnosis, date of end of treatment (if ended), current pain and discomfort, highest, lowest and average level of pain during the past week, average level of discomfort of pain during the past week and type of pain.

\section{Development of the Pain Flexibility Scale for Parents (PFS-P)}

Three psychologists acquainted with the concept of acceptance, both theoretically and clinically, were involved in the development process. A sketch of possible dimensions of acceptance in the context of pediatric cancer pain was formed. The basic structure of the Swedish version of the Chronic Pain Acceptance Questionnaire (CPAQ) was used in the development of the new scale. ${ }^{26,42}$ The CPAQ is a 20 -item self-report questionnaire for measuring acceptance in patients with chronic pain. It consists of two subscales, the Activity Engagement scale (11 items), which measures engagement in meaningful activities in the presence of pain, and the Pain Willingness scale (nine items), which measures willingness to experience pain and the degree to which the respondent tries to avoid or control pain. Higher scores indicate a higher level of acceptance. Cronbach's alpha of the CPAQ has been shown to be $0.78-0.82$, and it correlates negatively with measures of physical disability and psychological ill health. All items from the CPAQ with a clear chronic pain orientation, such as "I lead a full life even though I have chronic pain", were deleted. These were $\# 2$, \#4, \#5, \#6, \#9, \#10, \#12, \#13, $\# 14, \# 18$ and \#19. Nine items from the CPAQ were kept but re-formulated to capture the process of acceptance in the context of acute pain in children with cancer. These were \#1, $\# 3, \# 7, \# 8, \# 11, \# 15, \# 16, \# 17$ and \#20. For example, item 3 from the CPAQ "It's OK to experience pain" was altered to "Sometimes it feels ok for me when my child is pain", and item 11 "My thoughts and feelings about pain must change before I can take important steps in life" was altered to "My child's pain needs to pass before I can focus on anything else". Other, new items (28) were created, guided by the preliminary sketch of dimensions. A preliminary test version of the scale was handed out to two parents of children with cancer and four "lay" parents. Some items were adjusted according to this feedback. The final test version included 37 items. A seven-point Likert scale was used, where items were rated on a scale from $0=$ "Completely disagree" to $6=$ "Entirely agree". Twenty-two items were reversed for the statistical analyses.

\section{Measures used for validation}

The Pain Catastrophizing Scale for Parents (PCS-P) and the Acceptance and Action Questionnaire (AAQ-II) were used to assess convergent validity. The PCS-P is a 13 -item scale designed to measure catastrophizing thoughts in parents of children with pain. ${ }^{43,44}$ Respondents rate their level of agreement with statements such as "When my child is in pain, I worry all the time about whether the pain will end" and "When my child is in pain, I keep thinking about how badly I want the pain to stop" on a five-point Likert scale. Higher scores indicate a higher level of catastrophizing. Cronbach's alpha for the PCS-P has been shown to be 0.93 , and the scale correlates with measures of parental distress 
and child functioning and disability. The AAQ-II is designed to measure a general level of experiential avoidance. ${ }^{45,46}$ Participants rate their level of agreement with statements such as "I'm afraid of my feelings" and "I worry about not being able to control my worries and feelings" on a sevenpoint Likert scale. Higher scores indicate a higher level of experiential avoidance. Cronbach's alpha for the AAQ-II has been shown to be $0.78-0.88$, test-retest reliability over 3 months has been shown to be 0.81 and the scale correlates with a range of measures of mental health. The short version of six items was used. ${ }^{47}$

\section{Statistical analyses}

All statistical analyses were performed in IBM SPSS Statistics, version 20. ${ }^{48}$ Additionally, the Monte Carlo PCA program was used for parallel analysis. ${ }^{49}$ Initial analyses of the original test scale of 37 items were performed. Internal consistency was calculated to assess the appropriateness of factor analysis. Frequency distributions were examined to identify items that did not show sufficient variability in responses. Inter-item and item-total correlations were examined to identify items that did not correlate sufficiently with the other items and/or the total questionnaire. Intraclass correlation (ICC) was calculated to examine possible dependence in data between pairs. ${ }^{50} \mathrm{~A}$ one-way random model was used assessing the single measures value. ${ }^{51}$ An ICC of $<0.40$ indicates poor inter-rater agreement, between 0.40 and 0.59 fair, between 0.60 and 0.74 good and $>0.75$ excellent. ${ }^{52}$ Preliminary factor analysis was carried out and eigenvalue, scree plot, parallel analysis and pattern matrices were evaluated to select the number of factors for final analysis. Factor analysis was performed in the form of principal component analysis (PCA). Internal consistency and test-retest reliability were calculated for the total scale (Pearson) and the subscales (Spearman's rho). Correlations with other measures were performed to assess convergent validity (Spearman's rho). Correlation coefficients were interpreted according to
Cohen, ${ }^{53}$ where $r=0.10-0.29$ was considered small, $0.30-0.49$ medium and 0.5-1.0 large. For seven participants, only the M2 was valid. For statistical reasons, these were analyzed pertaining to M1.

\section{Results Descriptives}

The data from 243 parents of 158 children were included in the statistical analyses. Table 2 shows parents' reports of their children's level of pain. Regarding type of pain, at M1 $(n=185)$, seven parents reported pain due to the illness, 70 due to side effects of treatment, 16 due to medical procedures, 14 other type of pain and 78 reported pain due to several medical causes. At M2 ( $n=63)$, six parents reported pain due to the illness, 24 due to side effects of treatment, six due to medical procedures, six reported other type of pain and 21 reported pain due to several medical causes.

\section{Factor analysis}

Outliers were identified on items 2 and 22 and on the total scale. Given that there was very little difference between the mean and the trimmed mean, outliers were kept in the analyses. Frequency distributions showed that items 9, 13, 24 and 36 had somewhat limited variability. This was, however, considered acceptable. Internal consistency of the original 37 -item scale was good $(\alpha=0.87)$. Twelve items had low corrected item-total correlations $(<0.3)$ and were eliminated from further analysis. These were 1) "I brace myself when my child is in pain"; 12) "By thinking about something else I can handle the worry over my child being in pain"; 16) "I encourage my child to avoid movements or situations that might increase the pain"; 19) "Sometimes I feel that I am greater than my worries"; 20) "My worry is easier when I try to control it"; 22) "I react to my child's pain differently from one time to another"; 23) "If grit my teeth I can stand my child being in pain"; 26) "Sometimes it's unavoidable that my child experiences pain"; 32) "I try to help myself to

Table 2 Parents' reports of the children's level of pain and discomfort

\begin{tabular}{|c|c|c|c|c|c|c|}
\hline & \multicolumn{3}{|c|}{ Measurement I $(n=243)$} & \multicolumn{3}{|c|}{ Measurement $2(n=1 \mid 7)$} \\
\hline & Mean (SD) & Minimum & Maximum & Mean (SD) & Minimum & Maximum \\
\hline Current pain & $1.30(1.93)$ & 0 & 10 & $1.22(1.78)$ & 0 & 10 \\
\hline Current discomfort & $1.25(1.85)$ & 0 & 9 & $1.26(1.87)$ & 0 & 10 \\
\hline Most pain last week & $2.29(2.60)$ & 0 & 10 & $2.09(2.59)$ & 0 & 10 \\
\hline Least pain last week & $0.80(1.55)$ & 0 & 10 & $0.68(1.22)$ & 0 & 6 \\
\hline Average pain last week & $1.43(1.80)$ & 0 & 8 & $1.28(1.64)$ & 0 & 7 \\
\hline Discomfort last week & $1.58(2.05)$ & 0 & 10 & $1.50(1.99)$ & 0 & 10 \\
\hline
\end{tabular}

Note: Pain and discomfort was rated on a scale from $0=$ "No pain/discomfort at all" to $10=$ "Unbearably lot of pain/discomfort". Abbreviation: SD, standard deviation. 
cope with my worry over my child's pain"; 33) "If I try to feel what I really actually feel, it is easier"; 36) "Sometimes I am actually curious about my own worries over my child's pain" and 37) "The worry gets worse if I try to control it". The ICC was 0.195 indicating no dependence in data between pairs. Bartlett's test of sphericity was significant, the Kaiser-Meyer-Olkin (KMO) index was 0.91 and preliminary factor analyses showed no items that consistently loaded independently of the others. PCA was carried out on the remaining 25 items. Correlations between factors indicated interdependence between factors, and oblique rotation was used. The preliminary factor analyses extracted four factors with eigenvalues $>1$. Variance explained by a four-factor solution was $61 \%$. The scree plot showed a somewhat ambiguous result with an elbow at factors 2 and 4, indicating either one or three factors to retain. Parallel analysis indicated three factors to retain, while the component matrix indicated a twofactor solution. Further, the pattern matrix and the theoretical coherence between items were evaluated. Taken together, a three-factor solution with Promax rotation was chosen. Variance explained by a three-factor solution was $56 \% ; 39 \%$ by the first, $10 \%$ by the second factor and $7 \%$ by the third factor. All but two items ( 5 and 25) had factor loadings $>0.4$, and all but one item (5) had communalities $>0.3$. On considering both low factor loading and low communality, item 5 , "It is impossible for me to do anything when my child is in pain", was then eliminated. Hence, 24 items were included in the final solution. The theoretical analysis of the factors and their items yielded the following factor labels: 1) pain resistance, 2) valued action and 3) pain fusion. The first factor, pain resistance, is characterized by resisting, avoiding or attempting to control the feelings that having a child in pain implies. It also includes a kind of reactivity to their child's pain where the pain is seen as a threat and something that is impossible to live with. The second factor, valued action, is characterized by continuing to do things simultaneously while worrying over the child's pain, a way to live in the presence of pain and worry. The third factor, pain fusion, is characterized by evaluative language processing and rule-governed verbal behavior about pain, ie, judgments and verbal rules about pain itself and how it affects oneself and/or the child, and a literalization (ie, fusion) of these language processes. Note that for two items in factor 2 and one item in factor 3, the items represent the opposite pole of that factor compared to the other items. Table 3 shows the final factor solution. The score range is $0-144$ for the total scale, $0-54$ for the pain

Table 3 Factors, items, factor loadings and communalities for the final solution $(n=243)$

\begin{tabular}{|c|c|c|c|c|c|}
\hline \multirow{2}{*}{$\begin{array}{l}\text { Factor } \\
\mathrm{I}\end{array}$} & \multirow{2}{*}{$\begin{array}{l}\text { Factor label } \\
\text { Pain resistance }\end{array}$} & \multicolumn{2}{|c|}{ Item } & \multirow{2}{*}{$\begin{array}{l}\text { Factor } \\
\text { loading }\end{array}$} & \multirow{2}{*}{$\begin{array}{l}\text { Communality } \\
0.507\end{array}$} \\
\hline & & 35 & I do things to flee from my worry over my child's pain. & & \\
\hline & & 10 & I need to control my worry over my child's pain. & 0.671 & 0.605 \\
\hline & & 7 & I need to focus on getting rid of the worry over my child's pain. & 0.634 & 0.532 \\
\hline & & 17 & I have to struggle to do things when my child is in pain. & 0.623 & 0.533 \\
\hline & & 15 & I am afraid of my child's pain. & 0.587 & 0.638 \\
\hline & & 21 & My child's pain always feels like a threat to me. & 0.542 & 0.543 \\
\hline & & 34 & If I try to feel what I really actually feel, it is more difficult. & 0.530 & 0.308 \\
\hline & & 24 & Seeing my child in pain is too difficult for me. & 0.491 & 0.361 \\
\hline & & 30 & I can't think about anything else when my child is in pain. & 0.387 & 0.592 \\
\hline \multirow[t]{9}{*}{2} & Valued action & 27 & I continue doing things even when I am worried about my child being in pain. & 0.829 & 0.668 \\
\hline & & 14 & Even though it is difficult to see my child in pain I have learned that I can actually handle it. & 0.816 & 0.569 \\
\hline & & 8 & There are many things I can do simultaneously while worrying over my child being in pain. & 0.804 & 0.601 \\
\hline & & 29 & I feel that I can cope with my worry. & 0.755 & 0.721 \\
\hline & & 2 & Even if it is difficult for me to see my child in pain I know that I can handle it. & 0.751 & 0.510 \\
\hline & & 18 & I can focus on other things even while I am worried about my child being in pain. & 0.640 & 0.620 \\
\hline & & 28 & When my child is experiencing pain, I can do nothing else. & 0.548 & 0.618 \\
\hline & & 31 & $\begin{array}{l}\text { I continue to do things that are important to me even while I am worried about my child } \\
\text { being in pain. }\end{array}$ & 0.536 & 0.601 \\
\hline & & 25 & My child's pain needs to pass before I can focus on anything else. & 0.373 & 0.643 \\
\hline \multirow[t]{6}{*}{3} & Pain fusion & 4 & Sometimes it feels ok for me when my child is in pain. & 0.740 & 0.464 \\
\hline & & 3 & I refuse to allow my child to be in pain. & 0.716 & 0.450 \\
\hline & & 13 & I am very affected by my child being in pain. & 0.688 & 0.650 \\
\hline & & 6 & My child should never have to experience pain. & 0.644 & 0.466 \\
\hline & & 9 & My child being in pain makes me worried. & 0.580 & 0.606 \\
\hline & & II & Worrying over my child's pain is always difficult for me. & 0.454 & 0.535 \\
\hline
\end{tabular}


resistance subscale, $0-54$ for the valued action subscale and 0-36 for the pain fusion subscale.

\section{Reliability and validity}

Table 4 shows the mean, standard deviation, range (minimum-maximum), internal consistency and correlation coefficients for the total scale and the subscales. All correlation coefficients were large, except the coefficient between the pain fusion subscale and the AAQ-II that was medium. All correlations were significant $(p<0.01)$. All correlations were also calculated controlling for level of pain and change in level of pain, which had no or little effect on the correlations.

\section{Discussion}

The aim of this study was to develop and preliminarily evaluate an instrument to measure acceptance in parents of children experiencing pain during cancer treatment. A test version was developed based on theoretical considerations and the CPAQ. ${ }^{26}$ Factor analysis showed that a three-factor solution best represented the data. The final scale, the PFS-P, consisted of 24 items. The three subscales were pain resistance, valued action and pain fusion. Based on the theoretical analysis of the subscales, the term "Flexibility" was chosen instead of "Acceptance" for the total scale to indicate the somewhat greater width of the scale, including the subscales valued action and pain fusion. The total scale and the subscales all showed good internal reliability, temporal stability and good convergent validity. A fair sample for factor analysis was achieved with 243 respondents.

Parents of all children undergoing cancer treatment at the time of the study were offered participation in the study. To gain information regarding the pain status of the child, respondents were asked to rate their child's level of pain. For

Table 4 Mean, SD, score range, internal consistency and correlation coefficients for the total scale and the subscales

\begin{tabular}{|c|c|c|c|c|c|c|}
\hline \multirow[t]{2}{*}{ Scale } & \multirow{2}{*}{$\begin{array}{l}\text { Mean } \\
\text { (SD) }\end{array}$} & \multirow{2}{*}{$\begin{array}{l}\text { Score } \\
\text { range }\end{array}$} & \multirow{2}{*}{$\begin{array}{l}\text { Cronbach's } \\
\text { alpha }\end{array}$} & \multicolumn{3}{|c|}{ Correlations } \\
\hline & & & & $\begin{array}{l}\text { Test- } \\
\text { retest }\end{array}$ & PCS-P & AAQ-II \\
\hline PFS-P & $\begin{array}{l}69.7 \\
(24.8)\end{array}$ & $10-122$ & 0.93 & 0.87 & -0.84 & -0.63 \\
\hline $\begin{array}{l}\text { Pain } \\
\text { resistance }\end{array}$ & $\begin{array}{l}25.6 \\
(11.0)\end{array}$ & $0-54$ & 0.86 & 0.82 & -0.78 & -0.64 \\
\hline $\begin{array}{l}\text { Valued } \\
\text { action }\end{array}$ & $\begin{array}{l}33.5 \\
(10.3)\end{array}$ & $\mathrm{I}-54$ & 0.89 & 0.80 & -0.65 & -0.56 \\
\hline $\begin{array}{l}\text { Pain } \\
\text { fusion }\end{array}$ & $\begin{array}{l}10.6 \\
(7.2)\end{array}$ & $0-29$ & 0.81 & 0.76 & -0.69 & -0.40 \\
\hline
\end{tabular}

Abbreviations: SD, standard deviation; PFS-P, Pain Flexibility Scale for Parents; PCS-P, Pain Catastrophizing Scale for Parents; AAQ-II, Acceptance and Action Questionnaire - 2nd version. many respondents, their child had previously experienced pain but was not in pain at the time of study. In those cases, the measurements were completed retroactively. This can explain the low mean pain level. Despite the sub-optimal nature of retroactive measurements, the ratings were considered valid, taking into consideration the presumably strong experience of having a child in pain. Respondents were not asked about whether the child had previously experienced pain. Such a question would clearly have added important information. In the absence of such a control question, there was a risk of collecting data from parents whose children had not experienced pain during cancer treatment. Previous research $^{1}$ and clinical experience suggest, however, that with few exceptions, this would be an unlikely scenario. Further, the comments provided by the respondents who did not report any current pain revealed that their children had previously experienced pain. The risk of including "non-pain-respondents" in the study is therefore considered small. For those who explicitly declined participation, what was often given as a reason for declining was that the child had not experienced any pain during his/her treatment or that the pain was very limited in time or intensity. Again, considering previous research ${ }^{1}$ and clinical experience, the latter scenario would be more plausible.

Parents of one-third of the children participated in the study. Bearing in mind the often stressful and intense situation that undergoing cancer treatment brings about for these families, not responding to scientific studies is understandable. Expectations of a higher answering frequency may therefore be unrealistic. This is, however, something to keep in mind when generalizing the results of the study.

A frequent comment from respondents was that the source, type and level of pain considerably affected their ability to cope with it. It is not hard to imagine that if the source of the pain is known and/or the pain is benign, it is easier to accept and to stay psychologically flexible, whereas if the source of the pain is unknown and/or malignant, it gets harder. Parents of young and/or disabled children expressed a particular worry about not knowing how much pain their child experienced and whether the child was getting appropriate pain medication or not. Further, many respondents commented that they experienced a lack of psychosocial support during the treatment, that they were left alone with difficult feelings. Interventions naturally need to be tailored according to these experiences of the children and the parents.

This study is a preliminary validation of the PFS-P, and further validation is important, particularly if the scale is to be used for other populations. Note also that a Swedish 
version of the scale was developed and evaluated. An English version therefore needs to be validated. Further, sensitivity to change needs to be assessed.

\section{Conclusion}

A psychometrically sound scale for measuring acceptance in parents of children experiencing pain during cancer treatment is now available for use. This enables evaluating acceptancebased interventions targeting both parents and children in the context of pain in children with cancer. This in turn is a way to optimize interventions that may help both parents and children cope better in these difficult circumstances.

\section{Acknowledgments}

The Swedish Childhood Cancer Registry is greatly acknowledged for identifying eligible participants and supplying data. We would also like to thank the research nurses of the six pediatric oncology centers in Sweden for screening the data to avoid contact being made with parents of children who had recently gone into palliation or deceased. Professor Lance McCracken, Department of Psychology, King's College London, Professor Kevin Vowles, Department of Psychology, University of New Mexico, and Professor Christopher Eccleston, Department for Health, University of Bath, are also greatly acknowledged for their work in developing the CPAQ, upon which the test version of the PFS-P was partly developed. This work was supported by grants from the Swedish Childhood Cancer Foundation (PR2013-0058) and the Swedish Cancer Society (CAN2013/749).

\section{Disclosure}

The authors report no conflicts of interest in this work.

\section{References}

1. Twycross A, Parker R, Williams A, Gibson F. Cancer-related pain and pain management: sources, prevalence, and the experiences of children and parents. J Pediatr Oncol Nurs. 2015;32(6):369-384.

2. International Association for the Study of Pain (IASP) [webpage on the Internet]. 2008-2009 Global Year against Cancer Pain. [IASP Web site]. Available from: http://www.iasp-pain.org/GlobalYear/CancerPain. Accessed October 12, 2016.

3. Hedström M, Haglund K, Skolin I, von Essen L. Distressing events for children and adolescents with cancer: child, parent, and nurse perceptions. J Pediatr Oncol Nurs. 2003;20(3):120-132.

4. Pöder U, Ljungman G, von Essen L. Parents' perceptions of their children's cancer-related symptoms during treatment: a prospective, longitudinal study. J Pain Symptom Manage. 2010;40(5):661-670.

5. Hedén L, Pöder U, von Essen L, Ljungman G. Parents' perceptions of their child's symptom burden during and after cancer treatment. J Pain Symptom Manage. 2013;46(3):366-375.

6. Lautenbacher S, Huber C, Schöfer D, et al. Attentional and emotional mechanisms related to pain as predictors of chronic postoperative pain: a comparison with other psychological and physiological predictors. Pain. 2010;151(3):722-731.
7. Cioffi I, Michelotti A, Perrotta S, Chiodini P, Ohrbach R. Effect of somatosensory amplification and trait anxiety on experimentally induced orthodontic pain. Eur J Oral Sci. 2016;124(2):127-134.

8. McCracken LM, Gutiérrez-Martínez O. Processes of change in psychological flexibility in an interdisciplinary group-based treatment for chronic pain based on Acceptance and Commitment Therapy. Behav Res Ther. 2011;49(4):267-274.

9. Vowles K, Witkiewitz K, Sowden G, Ashworth J. Acceptance and commitment therapy for chronic pain: evidence of mediation and clinically significant change following an abbreviated interdisciplinary program of rehabilitation. J Pain. 2014;15(1):101-113.

10. Thorsell Cederberg J, Cernvall M, Dahl J, von Essen L, Ljungman G. Acceptance as a mediator for change in acceptance and commitment therapy for persons with chronic pain? Int J Behav Med. 2016;23(1): 21-29.

11. McCracken LM. Learning to live with the pain: acceptance of pain predicts adjustment in persons with chronic pain. Pain. 1998;74(1):21-27.

12. Veehof MM, Oskam MJ, Schreurs KMG, Bohlmeijer ET. Acceptancebased interventions for the treatment of chronic pain: a systematic review and meta-analysis. Pain. 2011;152(3):533-542.

13. American Psychological Association (APA) [webpage on the Internet] Evidence of Psychological Treatments [APA Web site]. Available from: $\mathrm{http} / / / \mathrm{www} . \operatorname{div} 12.0 \mathrm{rg} / \mathrm{psychological}$-treatments/disorders/chronic-orpersistent-pain/acceptance-and-commitment-therapy-for-chronic-pain/. Accessed October 12, 2016.

14. Hayes SC, Strosahl KD, Wilson KG. Acceptance and Commitment Therapy: The Process and Practice of Mindful Change. 2nd ed. New York, NY: The Guilford Press; 2012.

15. Kakigi R, Nakata H, Inui K, et al. Intracerebral pain processing in a Yoga Master who claims not to feel pain during meditation. Eur J Pain. 2005;9(5):581-589.

16. Grant J, Rainville P. Pain sensitivity and analgesic effects of mindful states in Zen meditators: a cross-sectional study. Psychosom Med. 2009;71(1):106-114.

17. Perlman DM, Salomons TV, Davidson RJ, Lutz A. Differential effects on pain intensity and unpleasantness of two meditation practices. Emotion. 2010;10(1):65-71.

18. Zeidan F, Gordon NS, Merchant J, Goolkasian P. The effects of brief mindfulness meditation training on experimentally induced pain. J Pain. 2010;11(3):199-209.

19. Zeidan F, Martucci KT, Kraft RA, Gordon NS, McHaffie JG, Coghill RC. Brain mechanisms supporting the modulation of pain by mindfulness meditation. J Neurosci. 2011;31(14):5540-5448.

20. Brown CA, Jones AKP. Meditation experience predicts less negative appraisal of pain: electrophysiological evidence for the involvement of anticipatory neural responses. Pain. 2011;150(3):428-438.

21. Choi KE, Rampp T, Saha FJ, Dobos GJ, Musial F. Pain modulation by meditation and electroacupuncture in experimental submaximum effort tourniquet technique (SETT). Explore. 2011;7(4):239-245.

22. Forsyth L, Hayes LL. The effects of acceptance of thoughts, mindful awareness of breathing, and spontaneous coping on an experimentally induced pain task. Psychol Rec. 2014;64(3):447-455.

23. Keogh E, Bond FW, Hanmer R, Tilston J. Comparing acceptance- and control-based coping instructions on the cold-pressor pain experiences of healthy men and women. Eur J Pain. 2005;9(5):591-598.

24. Buhle J, Wager TD. Does meditation training lead to enduring changes in the anticipation and experience of pain? Pain. 2010;150(3):382-383.

25. Kazdin AE, Nock MK. Delineating mechanisms of change in child and adolescent therapy: methodological issues and research recommendations. J Child Psychol Psychiatry. 2003;44(8):1116-1129.

26. McCracken LM, Vowles KE, Eccleston C. Acceptance of chronic pain: component analysis and a revised assessment method. Pain. 2004; 107(1):159-166.

27. Wicksell RK, Lekander M, Sorjonen K, Olsson GL. The Psychological Inflexibility in Pain Scale (PIPS) - statistical properties and model fit of an instrument to assess change processes in pain related disability. Eur J Pain. 2010;14(7):771.e1-771.e14. 
28. Reneman MF, Kleen M, Trompetter HR, et al. Measuring avoidance of pain: validation of the Acceptance and Action Questionnaire II-pain version. Int J Rehabil Res. 2014;37(2):125-129.

29. Peterson AM, Harper FWK, Albrect TL, et al. Parent caregiver selfefficacy and child reactions to pediatric cancer treatment procedures. J Pediatr Oncol Nurs. 2014;31(1):18-27.

30. Kazak AE, Penati B, Brophy P, Himelstein B. Pharmacologic and psychologic interventions for procedural pain. Pediatrics. 1998;102(1): 59-66.

31. Grootenhuis MA, Last BF. Adjustment and coping by parents of children with cancer: a review of the literature. Support Care Cancer. 1997; 5(6):466-484.

32. Klassen A, Raina P, Reineking S, Dix D, Pritchard S, O’Donnell M. Developing a literature base to understand the caregiving experience of parents of children with cancer: a systematic review of factors related to parental health and well-being. Support Care Cancer. 2007;15(7):807-818.

33. Rosenberg AR, Dussel V, Kang T, et al. Psychological distress in parents of children with advanced cancer. JAMA Pediatr. 2013;167(6): 537-543.

34. Blount RL, Corbin SM, Sturges JW, Wolfe VV, Prater JM, Denise James L. The relationship between adults' behavior and child coping and distress during BMA/LP procedures: a sequential analysis. Behav Ther. 1989;20(4):585-601.

35. Perrin EC, Ayoub CC, Willett JB. In the eyes of the beholder: family and maternal influences on perceptions of adjustment of children with a chronic illness. J Dev Behav Pediatr. 1993;14(2):94-105.

36. Phipps S, Mulhern RK. Family cohesion and expressiveness promote resilience to the stress of pediatric bone marrow transplant: a preliminary report. J Dev Behav Pediatr. 1995;16(4):257-263.

37. Fuemmeler BF, Brown RT, Williams L, Barredo J. Adjustment of children with cancer and their caregivers: moderating influences of family functioning. Fam Syst Health. 2003;21(3):263-276.

38. Phipps S, Long A, Hudson M, Rai SN. Symptoms of post-traumatic stress in children with cancer and their parents: effects of informant and time from diagnosis. Pediatr Blood Cancer. 2005;45(7): 952-959.

39. Robinson KE, Gerhardt CA, Vannatta K, Noll RB. Parent and family factors associated with child adjustment to pediatric cancer. J Pediatr Psychol. 2007;32(4):400-410.
40. Garthe RC, Sullivan T, Kliewer W. Longitudinal relations between adolescent and parental behaviors, parental knowledge, and internalizing behaviors among urban adolescents. J Youth Adolesc. 2015;44(4):819-832.

41. Moyer DN, Sandoz EK. The role of psychological flexibility in the relationship between parent and adolescent distress. J Child Fam Stud. 2015;24(5):1406-1418.

42. Vowles KE, McCracken LM, McLeod C, Eccleston C. The Chronic Pain Acceptance Questionnaire: confirmatory factor analysis and identification of patient subgroups. Pain. 2008;140(2):284-291.

43. Sullivan MJL, Bishop SR, Pivik J. The Pain Catastrophizing Scale: development and validation. Psychol Assessment. 1995;7(4):524-532.

44. Goubert L, Eccleston C, Vervoort T, Jordan A, Crombez G. Parental catastrophizing about their child's pain. The parent version of the Pain Catastrophizing Scale (PCS-P): a preliminary validation. Pain. 2006;123(3):254-263.

45. Hayes SC, Strosahl KD, Wilson KG, et al. Measuring experiential avoidance: a preliminary test of a working model. Psychol Rec. 2004; 54(4):553-578

46. Bond FW, Hayes SC, Baer RA, et al. Preliminary psychometric properties of the Acceptance and Action Questionnaire-II: a revised measure of psychological inflexibility and experiential avoidance. Behav Ther. 2011;42(4):676-688.

47. Lundgren T, Parling T. Swedish Acceptance and Action Questionnaire (SAAQ): a psychometric evaluation. Cogn Behav Ther. Epub 2016 Dec 9. $1-12$.

48. IBM. SPSS Statistics. Version 20.0.0. Armonk: IBM Corporation; 2012.

49. Pallant J. SPSS Survival Manual: A Step by Step Guide to Data Analysis Using IBM SPSS. 6th ed. Maidenhead: Open University Press; 2016.

50. Field A. Discovering Statistics Using SPSS: and Sex and Drugs and Rock 'n' Roll. 3rd ed. London: SAGE; 2009.

51. Landers $\mathrm{R}$ [webpage on the Internet]. Computing Intraclass Correlations (ICC) as Estimates of Interrater Reliability in SPSS. [The Winnower Web site]. Available from: https://thewinnower.com/papers/1113-computing-intraclass-correlations-icc-as-estimates-of-interrater-reliabilityin-spss. Accessed 12 October, 2016.

52. Cicchetti DV. Guidelines, criteria, and rules of thumb for evaluating normed and standardized assessment instruments in psychology. Psychol Assess. 1994;6(4):284-290.

53. Cohen J. Statistical Power Analysis for the Behavioral Sciences. 2nd ed. Hillsdale: L. Erlbaum Associates; 1988.
Journal of Pain Research

\section{Publish your work in this journal}

The Journal of Pain Research is an international, peer reviewed, open access, online journal that welcomes laboratory and clinical findings in the fields of pain research and the prevention and management of pain. Original research, reviews, symposium reports, hypothesis formation and commentaries are all considered for publication.

\section{Dovepress}

The manuscript management system is completely online and includes a very quick and fair peer-review system, which is all easy to use. Visit http://www.dovepress.com/testimonials.php to read real quotes from published authors. 